\title{
A Framework Proposal for Digital Interventions in Perinatal Education: The Result of a Content Analysis to WHO Intra- Partum Care Recommendations
}

\author{
Carla V. Leite \\ Department of Communication and Art/Digimedia, and Department of Education and Psychology, \\ University of Aveiro, Aveiro, Portugal.
}

\author{
Ana Margarida Almeida \\ Department of Communication and Art/Digimedia, University of Aveiro, Portugal.
}

\begin{abstract}
Purpose - This research proposes a framework to guide the development and analysis of digital interventions, namely through mobile applications, regarding labor and birth. By complying with current scientific evidence, it aims to contribute to the safeness and completeness of perinatal health education targeting expectant parents.

Design/Methodology/Approach - A content analysis was conducted on a document containing WHO guidelines for intra-partum, considering the following categories: Timeframe, Care options, Category of recommendation, in order to create a dataset clearly distinguishing between Recommendations and NonRecommendations. Context-specific and Research-context recommendations, details from dosages, measurements and timings, infant care and non-immediate postpartum topics were considered out of the scope of this study.

Findings - The results were summarized in a table, ready to be used as a dataset, including the following sixteen Care options ranging from health, well-being and/or rights: Respect, Communication, Companionship, Pregnant person's monitoring, Status, Fetal monitoring, Pain relief, Pain management, Amenities, Labor delay prevention, Progress, Freedom of choice, Facilitation of birth, Prevention of postpartum hemorrhage, Umbilical cord care, and Recovery. These were distributed across six timeframes: Always, Admission, First, Second and Third stage of labor, and Immediate Postpartum. In addition, Recommendations and Non-Recommendations are displayed in different columns.

Originality - This transdisciplinary research intends to contribute to: future research on perinatal education; the creation of digital interventions, namely m-health ones, targeting expectant parents by providing a framework of content coverage; the endorsement of the rights to Information and to decision-making. Ultimately, when put into practice, the framework can impact self-care through access to Perinatal education.
\end{abstract}

Keywords Informed-decision; Digital Interventions; Self-care; Reproductive Rights; Labor; Birth; Pregnancy; Perinatal Education; Childbirth Education; Mobile Applications; m-health; e-health; Health systems; Preventive healthcare; Recommendations; WHO Guidelines.

Paper type Research Paper 


\section{Introduction}

When it comes to pregnancy, labor and birth, everyone has an opinion, a story to tell or an experience to share (Kay et al., 2017). Despite the fact that common sense and evidence-based science are two different things, they tend to blend when fear and uncertainty take the lead (Zakerihamidi et al., 2015). The primary goal of an expectant parent may be keeping the fetus safe and healthy, but first they need to know how to take care of themselves, namely in what concerns health during pregnancy and childbirth, by being able to make informed-decisions (Coxon et al., 2017).

One of the first moments this topic started to gain public attention occurred in 1948, during the signing of the Universal Declaration of Human Rights, in which the importance of accessing Information and Communication through different media (Article 19), Education (Article 26) and Health (Article 25) was affirmed (United Nations General Assembly, 1948). Twenty years later, during the Tehran Conference, recommendations to support education on family planning were established (United Nations, 1968). By 1994, during the Cairo Conference, sexual and reproductive rights were emphasized, and in the following year, during the Beijing Conference, it became clear that those rights needed to be endorsed along with other fundamental ones, and that there was still a long way to go (UNFPA, 1995).

Over the past decades, Maternal Care, which includes comprehensive sexual education, has been highlighted on the political agenda (Carreno et al., 2014). United Nations had listed it as one of the eight Millennium Development Goals for 2015 (United Nations, 2015a), and currently the topic fits at least three of the seventeen Sustainable Development Goals (SDG) for 2030: 3 - Good Health and Well-being; 4 Quality Education; 5 - Gender Equality. In addition, achieving better family planning can also contribute to the reduction of poverty, hunger, inequalities, and help develop sustainable communities in the long term (Goals 1, 2, 10 and 11, accordingly) (United Nations, 2015b).

Every year, approximately 140 million women give birth, and despite the majority of pregnancies occurring without risk factors, the incidence of complications during labor increases the risk of serious morbidity and death, for both women and newborns (Kassebaum et al., 2013; Say et al., 2014). The most impactful strategy identified for reducing this risk is improving the quality of care around the time of birth (Bhutta et al., 2014). The work of the World Health Organization (WHO) on this matter, not only focuses on survival, but also aims for women and children to reach their full potential for health and life (WHO, 2018).

Even though: a) antenatal (related mainly to pregnancy) and perinatal education (related to the period ranging from labor to birth) being affirmed as playing a relevant role for a positive birth experience (HidalgoLopezosa et al., 2017; Afshar et al., 2017); b) self-care interventions to meet Sexual and Reproductive Health and Rights importance being recognized; c) the potential of health communication and promotion being promoted (WHO, 2019b); d) Digital Technologies and Platforms being listed as one of the Places of 
Access to comply with several human rights (WHO 2019a; 2019b); no truly digital interactive services provided or endorsed by $\mathrm{WHO}$, regarding perinatal education and targeting expectant parents, were found (Norris and Ford, 2017).

Furthermore, none of the studies found and herein presented to support the state of the art of digital interventions regarding perinatal education (including several systematic reviews), mentioned WHO guidelines as a reference in building their dataset.

Aiming to endorse the Right to Information and to Informed Decision-making (WHO, 2019a), this article proposes a framework concerning safeness and completeness of content, ready to be used in future research analysis within this scope, and to guide the development of related mobile applications, and possibly other digital services.

The framework proposal is focused on evidence-based data, so it does not contemplate subjective data, (i.e. testimonials from other parents, doulas or health professionals), avoiding bias from personal perceptions, beliefs, fears, and motivations, since each pregnant person' expectations and childbirth experiences are unique.

\subsection{From Information to Knowledge and Decision}

The currently rising health paradigm involves the individuals in an active way, in the center of care, so health promotion can start with prevention. Individuals and communities are empowered to maintain and enhance their health and well-being, and are recognized as conscious, capable of self-care through education and support (WHO, 2019a). It acknowledges the need for free, prior and clarified voluntary consent and refusal, of any clinical treatment, procedure, and intervention, based on information regarding the risks, benefits, and alternatives of care, as well as taking in consideration the circumstances, personal beliefs and priorities, a process known as: informed-decision making (Queensland Health, 2017).

Individual health literacy level is a factor that unquestionably constrains the ability of making suitable decisions regarding one's health. It thus includes dimensions such as self-confidence and social networks, along with literacy and numeracy (Delanoë et al., 2016). So, low levels of health literacy are reported to negatively affect the condition of one's health due to minor preventive practices and low autonomy, leading to a more frequent use of emergency services (Espanha and Ávila, 2016).

To make an informed decision related to health care in ideal conditions, experts on the scientific evidence support the individual who will make a decision, participating in a communication channel so they can share their views with each other (Stirling et al., 2018). Network and knowledge societies demand an increase of quality communication channels so people can "have the capabilities not just to acquire information but also 
to transform it into knowledge and understanding, which empowers them to enhance their livelihoods and contribute to the social and economic development of their societies" (UNESCO, 2013, p. 18). So by proposing and commenting on health decisions, the individuals should be able to take care of themselves, their family and their community (Machado et al., 2007).

Informed Decision-Making regarding birth is accepted as an established and regulated right in many developed countries for some years now, incorporated in agreements, such as English common law, Napoleonic Code, US Constitution and Bill of Rights, Helsinki Declaration, and it is endorsed by global organizations, so that it is also perceived and approved as a right in low and middle income countries by the World Health Organization, Médecins sans Frontieres and Amnesty International (Krogstad et al., 2010).

Some studies show that pregnant people who actively participated in decisions regarding the mode of delivery felt more satisfied and had a better perception about the birth. They show a deep impact in the perception of pregnant people's satisfaction with birth, with consequences on the feelings between the pregnant person and the neonate, namely bonding (Figueiredo et al., 2012).

\subsection{Mobile applications for Childbirth Literacy}

Expectant parents have been using digital technologies to search for information and support (Robinson et al., 2018; Bjelke et al., 2016; Sayakhot at al., 2016), expanding its usage according to the digital technology era by: consulting websites and blogs; communicating on discussion forums; interacting through social websites; generating and controlling data through mobile media and ubiquitous connections (Zhu, 2019; Lupton, 2016). This promotes not only receiving and seeking behaviors, but also the creation and share, reaching an increasingly broader audience (Zhu, 2019; Wallwiener et al., 2016).

In 2013, Derbyshire and Dancey study reported that health and well-being mobile applications (apps) were already popular among expectant parents, with an average of three pregnancy web or mobile applications being downloaded during their gestational period. In 2014, mobile apps for pregnancy outnumbered other health-related topics, and were reported as the first digital resources to seek pregnancy-related information (Kraschnewski et al., 2014). Tripp et al. (2014) study showed that pregnancy-related information apps end up supporting self-care matters, such as reducing the need to visit the hospital, relieving anxiety by educating consumers, and, allowing women to understand their own conditions.

Notwithstanding, Lee and Moon (2014) concluded that e-health apps should be developed and managed together with qualified healthcare professionals, since they pointed out that the most frequently weakness found was Lack of Credibility, since mobile apps' description did not generally contain advice or safety 
information to serve as healthcare tools, and therefore they could not be considered completely safe. Previous research shows that women are not necessarily aware of what information credibility involves, with several studies suggesting that individuals using the internet do not know how to evaluate the accuracy of online information, do not remember from where they retrieved it and do not consistently check the authorship (Huberty et al., 2013).

Besides the Internet being widely used across the globe as an effective tool to gather pregnancy-related information (Bjelke et al., 2016; Sinclair et al., 2018), digital technologies to support the perinatal period were reported as one of the major unmet needs of pregnant people which could be significantly improved (Robinson et al., 2018).

\section{World Health Organization Guidelines Relevance}

Disrespectful and undignified care is prevalent in many health care facilities globally, violating human rights and acting as a barrier to access to intra-partum care services (Bohren et al., 2014). In many parts of the world, the prevailing model of intra-partum care enables the health care provider to control the birthing process, which may expose healthy pregnant people to unnecessary medical interventions. According to WHO (2018), over the past two decades, labor practices to initiate, accelerate, terminate, regulate and monitor the physiological process of labor increased substantially. Studies show that a considerable amount of healthy pregnant people undergo at least one intervention during labor and birth (Coulm et al., 2012; Euro-Peristat Project, 2013). WHO (2018, p.8) reported that "women in labour continue to be subjected to inefficient and potentially harmful routine interventions, such as perineal shaving, enemas, amniotomy, intravenous fluids, antispasmodics and antibiotics for uncomplicated vaginal births". This interventionist approach, the medicalization of the processes, tends to weaken and undermine the pregnant person's own capability to give birth, and does not take in consideration their personal needs, values and preferences. Instead of improving outcomes for women and babies, it has been negatively impacting the childbirth experience (Renfrew et al., 2014).

For the past two decades, WHO (2016) has been issuing technical guidance regarding healthcare for pregnant people, advocating the progressive change of global practices of maternity services. However, besides mortality, other indicators impact the labor and birth experience, and these factors need to be addressed to increase the adoption and establish consolidation of the substantial promoted advances (Madaj et al., 2017).

WHO established a Global Strategy for Women's, Children's and Adolescents' Health (2016-2030), and released recommendations addressing specific aspects of labor management, advocating for a sound foundation for maternal healthcare and well-being. WHO comprehensive guidelines highlight the relevance 
of women-centered care, with a holistic, up-to-date, evidence-based, comprehensive and human-rights approach, aimed at the quality of perinatal care as safe and a positive experience for women and relatives. It addresses routine antenatal care, informed by a systematic review of women's views, which shows they want a positive experience during that particular period. It lists 49 recommendations aimed at supporting women in maintaining physical and socio-cultural normality, maintaining a healthy pregnancy, having an effective transition to positive labor and birth and achieving positive parenthood. They are subdivided into five data categories: nutritional intervention, maternal and fetal assessment, preventive measures, physiological symptoms and health systems. It also underlines the importance of tailoring 23 of those recommendations as context-specific, namely because their actual costs are not feasible for a global guideline, considering the disparities between low-, middle- and high-income settings (WHO, 2016). However, this requires an additional effort to interpret and apply at a national level (Norris and Ford, 2017).

Improving quality and care experience is as important as clinical care provision in achieving the desired person-centered outcomes. However, non-clinical intra-partum practices, such as emotional support, effective communication and respectful care, are not commonly regarded as a priority, even though they are fairly inexpensive to implement. Similarly, pregnant people's values regarding birthing options and their choices during first and second stages of labor are not consistently respected and promoted, conditioning the experience of birth for the person and their family (Tunçalp et al., 2015).

To measure the Maternal birth experience, WHO (2018) took qualitative and systematic reviews focused on women's views and outcomes into consideration, namely: maternal satisfaction with care; women's mental and psychological health assessment; rating of childbirth experience and sense of control.

In 2018, WHO launched an intra-partum care guideline formulated to inform and guide the decision-making process aimed at achieving the best trade-off between effects, values, resources, equity, acceptability and feasibility (WHO, 2018). It is focused on promoting a positive childbirth experience, defining it as "one that fulfils or exceeds a woman's prior personal and sociocultural beliefs and expectations (...). It is based on the premise that most women want a physiological labor and birth, and to have a sense of personal achievement and control through involvement in decision-making, even when medical interventions are needed or wanted" (WHO, 2018, p.1).

Both documents are based on scientific evidence so, naturally, they are updated from time to time to take into consideration the last scientific endeavors (WHO, 2018; WHO, 2016). However, there is no doubt this documentation is a great leap for person-centered care policies and its main target audience is neither the general public nor pregnant people in particular, but rather: "national and local public health policy-makers, implementers and managers of maternal and child health programs, health care facility managers, nongovernmental organizations, professional societies involved in the planning and management of maternal and child health services, health care professionals (including nurses, midwives, general medical practitioners and obstetricians) and academic staff involved in training health care professionals" (WHO, 
2018, p.1).

Moreover, the guidelines are available to download for free on WHO's website, and its format is similar to a print-based approach (PDF), without any kind of interactivity. Also, WHO does not provide mobile applications or web platforms on this matter. This lack of digital interaction is a passive approach to dissemination which has been criticized for being insufficient (Norris and Ford, 2017). It is obvious that $\mathrm{WHO}$ is working on this matter, since it released WHO guideline recommendations on digital interventions for health system strengthening, and it will soon be launching a digital accelerator kit regarding Sexual and Reproductive health (Norris and Ford, 2017; Barreix et al., 2020). However, according to information available at the present date, it targets health program managers, software developers and implementers of digital systems, aiming to establish common ground for health information content between them (WHO, 2019b, 2019c).

Studies show that three roles need to be involved for planning and implementing educational and outreach initiatives in health care: a) health professionals, b) managers and c) population, both individually and collectively. The first ones, the care providers, value prevention, health promotion and healing practices. Managers can support these professionals with planning, organization, and strategy. Lastly, the population, need to build their knowledge and their autonomy in health (Falkenberg et al., 2014). The UNICEF report (2018) goes even further, clarifying a set of five main archetypes to build a team to develop digital health interventions for lasting impact, their roles in the process, possible tools to be used, and methodologies to be adopted. It acknowledges the importance of observing, interacting and designing with, and for, the people who will use it.

Notwithstanding, none of the studies collected to understand the state of the art, including systematic reviews, reported the usage of WHO guidelines as a referential for their analysis. Following ad hoc datasets has implications on how those digital interventions are being classified in terms of content safeness and completeness.

\section{Framework Proposal for Digital interventions}

Perinatal education for parents-to-be, good communication between them and healthcare professionals, along with responsiveness and flexibility of healthcare professionals during labor and birth, seems to be determinant in persons' care, in order for birth to be a positive experience (Hidalgo-Lopezosa et al., 2017; Afshar et al., 2017).

As a reinforcement tool for childbirth literacy, to help clarify definitions, demonstrate the process and explain interventions, for the purpose of discussion of options, perceptions, beliefs, fears, and motivations, in order 
to create awareness, build knowledge, and promote informed decisions, there are specific content formats which can be included on the digital interventions, such as illustrations, photos, videos, audio-recordings, texts and diagrams (Dalton et al., 2018; da Silva et al., 2016; Lutenbacher et al., 2014). The decision of which format will best overcome a specific barrier, fill the communication gap and address the right challenge, may involve an immersive ethnographic approach. If adopting a human-centered approach, it will count with future users' collaboration during the design process (UNICEF, 2018).

Aligned with the scope of this study (solely on the labor and birth period, and on the pregnant person, therefore excluding infant care and postpartum days after birth topics), a Content Analysis was conducted on the 5-page list, supported by the 200 pages which follow, of the guidelines document (WHO, 2018). This summary list includes i) a set of Care options; ii) provides a description how to behave accordingly, and iii) defines the Category of Recommendation as: Recommended, Not-recommended, Context-specific recommendation and Research-context recommendation.

The founded Care options (i) were clustered according to its timeframe (see Table I, first column), and simplified as keywords (see Table I, second column). This organization and terminology complied with the description found on the textual description. Therefore, Category of Recommendation was split in two: a single column for Recommendations, and another one for the Non-Recommendations; in order to be possible to read them separately (see Table I, third and fourth columns). The dash symbol was inserted on the table when no Recommendation or Non-recommendation was found related to a specific Care Option. Extensive technical terminology was avoided (see Note 1), and it was adopted inclusive language (see Note 2), to build the following table. 
Table I. Framework proposal complying with WHO recommendations and non-recommendations for intrapartum care (authors' proposal)

\begin{tabular}{|c|c|c|c|}
\hline Timeframe & Care option & Recommended & Not recommended \\
\hline \multirow{3}{*}{ Always } & Respect & $\begin{array}{l}\text { Dignity; Privacy; Confidentiality; } \\
\text { Informed choice; Continuous support. }\end{array}$ & Harm, Mistreatment \\
\hline & Communication & $\begin{array}{l}\text { Effective; Simple and culturally } \\
\text { acceptable methods. }\end{array}$ & - \\
\hline & Companionship & Companion of choice. & - \\
\hline \multirow[t]{2}{*}{ Admission } & $\begin{array}{l}\text { Pregnant person's } \\
\text { monitoring }\end{array}$ & $\begin{array}{l}\text { Contractions; Dilatation; Changes of } \\
\text { cervix; Digital vaginal examination. }\end{array}$ & $\begin{array}{l}\text { Clinical pelvimetry; Enema; } \\
\text { Perineal/Pubic shaving; Vaginal } \\
\text { cleansing. }\end{array}$ \\
\hline & Status & Inform the expectant parents. & Unrealistic progress expectations. \\
\hline \multirow{5}{*}{$\begin{array}{l}\text { First stage } \\
\text { of labor }\end{array}$} & Fetal monitoring & $\begin{array}{l}\text { Intermittent auscultation with Doppler } \\
\text { ultrasound or Pinard fetal } \\
\text { stethoscope. }\end{array}$ & Cardiotocography. \\
\hline & Pain relief & $\begin{array}{l}\text { Epidural Analgesia; Parenteral } \\
\text { Opioids. }\end{array}$ & - \\
\hline & Pain management & $\begin{array}{l}\text { Relaxation techniques (muscle, } \\
\text { breathing, music and mindfulness) } \\
\text { and Manual (massage and warm } \\
\text { packs). }\end{array}$ & Active management \\
\hline & Amenities & $\begin{array}{l}\text { Oral fluid and food; Mobility and } \\
\text { Upright position. }\end{array}$ & - \\
\hline & $\begin{array}{l}\text { Labor delay } \\
\text { prevention }\end{array}$ & Duration as personal and on average. & $\begin{array}{l}\text { Pain relief; Amniotomy; Oxytocin; } \\
\text { Antispasmodic agents; Intravenous } \\
\text { fluids. }\end{array}$ \\
\hline \multirow{3}{*}{$\begin{array}{l}\text { Second } \\
\text { stage of } \\
\text { labor }\end{array}$} & Progress & $\begin{array}{l}\text { Inform the expectant parents; } \\
\text { Duration as personal and on average. }\end{array}$ & - \\
\hline & Freedom of choice & Position; Method of pushing. & - \\
\hline & Facilitation of birth & $\begin{array}{l}\text { Perineal trauma prevention (massage, } \\
\text { warm compresses, hands-on). }\end{array}$ & Episiotomy; Fundal pressure. \\
\hline \multirow{2}{*}{$\begin{array}{l}\text { Third stage } \\
\text { of labor }\end{array}$} & $\begin{array}{l}\text { Prevention of } \\
\text { Postpartum } \\
\text { Hemorrhage }\end{array}$ & Prophylactic uterotonics. & Uterine massage. \\
\hline & Umbilical cord care & $\begin{array}{l}\text { Delayed clamping; Controlled cord } \\
\text { traction. }\end{array}$ & - \\
\hline $\begin{array}{l}\text { Immediate } \\
\text { Postpartum }\end{array}$ & Recovery & Uterine tonus assessment. & Antibiotics. \\
\hline
\end{tabular}


Since, the analyzed guidelines document targets a clinical specialized audience on intra-partum care, details from dosages, measurements and timings were excluded from this study, as they are out of the scope of expectant parents' decisions. Also, Context-specific recommendations and Research-context recommendations were not included in the proposal, since they are a WHO effort to provide support for different settings and according to the available means, as acknowledged previously.

\section{Implications for Practice and Research}

The proposed framework is intended to be used as: a) a reference for categories in future studies, systematic reviews in particular, when analyzing existent digital educational interventions, namely mobile applications, related to the Perinatal period, contributing directly for health communication systems and digital health literacy research fields; b) a dataset in order to support the creation of content, information architecture, development, implementation, and ultimately the decisions from product managers and digital strategists, when creating digital interventions related to labor and birth, namely mobile applications, targeting expectant parents as their main audience.

The primary stakeholders of this framework are researchers, product managers, developers, designers, digital strategists and content creators. Expectant parents, healthcare workers, namely the ones involved in the childbirth process, and childbirth educators can be counted as the secondary stakeholders, since they could be affected by the outcome of the digital interventions.

If childbirth educators include the digital interventions as part of their classes and endorse them, or even if the expectant parents just find and use them, they may be able: to leverage their knowledge, to be more autonomous, to self-care, to take preventive actions, and to make informed decisions. In sum, to obtain higher perinatal health literacy to be able to better exercise their Right to Information and the Right to Informed Decision-making regarding labor and birth, and trigger rich discussions with the healthcare workers to aim a positive birth experience (Hidalgo-Lopezosa et al., 2017; Afshar et al., 2017).

The innovation of the study relies on filling an existent gap in the literature, since there is a lack of frameworks based on scientific evidence to create and analyze digital interventions for Perinatal Education, despite the fact that Lack of Credibility is a concern in e-health, as already acknowledged. The proposal is intended to provide safe and reliable dataset, and become a reference for other studies and projects. 


\section{Conclusion}

The literature provides a clear insight that only by endorsing individual health literacy among expectant parents and promoting it through technologies they are familiar with, would it be possible to create meaningful digital interventions as a preventive healthcare measure, aiming to build knowledge, to endorse informed-decisions, and to raise awareness for self-care (Delanoë et al., 2016; Wallwiener et al., 2016; WHO, 2019a), all rights recognized in reproductive health care in current times.

Despite mobile apps being widely used among expectant parents, with some being endorsed by health professionals, they are not necessarily considered complete and safe as e-health tools by the studies found (Derbyshire and Dancey, 2013). However, considering the state of the art collected, which includes several systematic reviews, the studies seem to fail to analyze how the mobile apps do/do not comply with the evidence-based data provided and updated by WHO, commonly using their own criteria to analyze content coverage.

The results from the Content Analysis conducted to WHO intra-partum guidelines (WHO, 2018) were clustered and categorized in a single table, listing Recommended and Non-Recommended Care Options, over different Timeframes of the labor and birth period (see Note 1). This framework proposal can be used for conducting analysis to, or the development of, digital interventions, in particular mobile applications. Future studies need to be conducted to extend the proposed framework to other domains of healthcare, including the topics determined to be outside the scope of this study, and to understand its applicability to other media channels.

Note 1 - The framework may need to be updated over time, according to scientific endeavors highlighted by WHO.

Note 2 - Although woman/she/her and partner/father are commonly used in the references, and consequently in citations, in this article and proposed framework, broader terms, such as pregnant person, expectant parents and companion were used accordingly, regardless of their gender identity and expression, sexual orientation; thereby, not complying with heteronormativity (Darwin and Greenfield, 2019). 


\section{Acknowledgments}

This research was supported by the Portuguese National Funding Agency for Science, Research and Technology (FCT - Fundação para a Ciência e a Tecnologia), through the Doctoral Programme in Technology Enhanced Learning and Societal Challenges (TELSC) (PD/00173/2013), under the research grant PD/BD/143077/2018.

\section{Conflict of interest}

The authors have no competing interests.

\section{References}

Afshar, Y., Mei, J. Y., Gregory, K. D., Kilpatrick, S. J., and Esakoff, T. F. (2017), "Birth plans Impact on mode of delivery, obstetrical interventions, and birth experience satisfaction: A prospective cohort study", Birth, Vol. 45, No. 1, pp. 43-49, available at: https://doi.org/10.1111/birt.12320

Barreix, M., Lawrie, T. A., Kidula, N., Tall, F., Bucagu, M., Chahar, R., and Tunçalp, Ö. (2020), "Development of the who antenatal care recommendations adaptation toolkit: a standardised approach for countries", Health Res Policy Sys, Vol. 18, available at: https://doi.org/10.1186/s12961-020-00554-4

Bhutta, Z. A., Das, J. K., Bahl, R., Lawn, J. E., Salam, R. A., Paul, V. K., . . Walker, N. (2014), "Can available interventions end preventable deaths in mothers, newborn babies, and stillbirths, and at what cost?", The Lancet, 384, pp. 347-370.

Bjelke, M., Martinsson, A. K., Lendahls, L., and Oscarsson, M. (2016). "Using the internet as a source of information during pregnancy - a descriptive cross-sectional study in Sweden", Midwifery, Vol. 40, pp. 187-191.

Bohren, M. A., Hunter, E. C., Munthe-Kaas, H. M., Souza, J. P., Vogel, J. P., and Gülmezoglu, A. M. (2014), "Facilitators and barriers to facility-based delivery in low- and middle-income countries: a qualitative evidence synthesis", Reprod Health, Vol. 11, No. 71.

Carreno, I., Bonilha, A. L. d. L., and da Costa, J. S. D., (2014), "Temporal evolution and spatial distribution of maternal death", Revista de saúde pública, Vol. 48, No. 4, pp. 662-670.

Coulm, B., Ray, C. L., Lelong, N., Drewniak, N., Zeitlin, J., and Blondel, B. (2012), "Obstetric interventions for low-risk pregnant women in france: do maternity unit characteristics make a difference?" Birth, 39, pp. 183-191.

Coxon, K., Chisholm, S., Malouf, R., Rowe, R. and Hollowell, J. (2017), "What influences birth place preferences, choices and decision-making amongst healthy women with straightforward pregnancies in the UK? A qualitative evidence synthesis using a 'best fit' framework approach." BMC 
Pregnancy and Childbirth, No. 17.

Cummins, C. O., Prochaska, J. O., Driskell, M. M., Evers, K. E., Wright, J. A., Prochaska, J. M., and Velicer, W. F. (2003), "Development of review criteria to evaluate health behavior change websites", Journal Health Psychology, Vol. 8, No. 1, pp. 55-62.

da Silva, E. P., de Lima, R. T., and Osório, M. M. (2016), Impacto de estratégias educacionais no pré-natal de baixo risco: revisão sistemática de ensaios clínicos randomizados. Ciência and Saúde Coletiva, Vol. 21 No. 9, pp. 2935-2948, available at: https://doi.org/10.1590/1413-81232015219.01602015 Dalton, J. A., Rodger, D., Wilmore, M., Humphreys, S., Skuse, A., . . , and Clifton, V. L. (2018), "The health-e babies app for antenatal education: Feasibility for socially disadvantaged women" PLoS ONE, Vol.13, No. 5, e0194337.

Darwin, Z., and Greenfield, M., (2019), "Mothers and others: The invisibility of LGBTQ people in reproductive and infant psychology", Journal of Reproductive and Infant Psychology, Vol. 37, No.4, pp. 341-343, available at: https://doi.org/10.1080/02646838.2019.1649919

Delanoë, A., Lépine, J., Portocarrero, M. E. L., Robitaille, H., Turcotte, S., Lévesque, I., . . Légaré, F., (2016), "Health literacy in pregnant women facing prenatal screening may explain their intention to use a patient decision aid: a short report." BMC Research Notes, Vol. 9.

Derbyshire, E., and Dancey, D. (2013). "Smartphone medical applications for women's health: What is the evidence-base and feedback?", International Journal of Telemedicine and Applications, 782074, available at: https://doi.org/10.1155/2013/782074

Doty, J. L., and Dworkin, J. (2014). “Online social support for parents: A critical review”. Marriage and Family Review, Vol. 50, pp. 174-198.

Espanha, R., and Ávila, P. (2016), "Health literacy survey Portugal: A contribution for the knowledge on health and communications." Procedia Computer Science, Vol. 100, pp. 1033-1041.

Euro-Peristat Project. (2013). "The health and care of pregnant women and babies in Europe in 2010", European Perinatal Health Report, available at: https://www.europeristat.com/images/European Perinatal Health Report_2010.pdf

Falkenberg, M. B., Mendes, T. d. P. L., de Moraes, E. P., and de Souza, E. M., (2014) "Educação em saúde e educação na saúde: conceitos e implicações para a saúde coletiva”, Ciência and Saúde Coletiva, Vol. 19, No. 3, pp. 847-852.

Figueiredo, B., Costa, R., and Pacheco, A. (2012). "Experiência de parto: Alguns factores e consequências associadas", Análise Psicológica, Vol. 20, No. 2, pp. 203-217.

Hidalgo-Lopezosa, P., Hidalgo-Maestre, M., and Rodríguez-Borrego, M. A. (2017), Birth plan compliance and its relation to maternal and neonatal outcomes. Revista Latino-Americana de Enfermagem, Vol. 25, available at: https://doi.org/10.1590/1518-8345.2007.2953

Huberty, J., Dinkel, D., Beets, M. W., and Coleman, J. (2013), "Describing the use of the internet for health, physical activity, and nutrition information in pregnant women." Maternal and Children Health Journal, Vol. 17, pp. 1363-1372. 
Kassebaum, N. J., Bertozzi-Villa, A., Coggeshall, M. S., Shackelford, K. A., Steiner, C., Heuton, K. R.,. . . Lozano, R. (2013), "Global, regional, and national levels and causes of maternal mortality during 1990-2013: a systematic analysis for the global burden of disease study 2013". The Lancet, Vol. 384, pp. 980-1004.

Kay, L., Downe, S., Thomson, G. and Finlayson, K. (2017) "Engaging with birth stories in pregnancy: a hermeneutic phenomenological study of women's experiences across two generations", BMC Pregnancy and Childbirth, Vol. 17, pp. 283.

Kraschnewski, L. J., Chuang, H. C., Poole, S. E., Peyton, T., Blubaugh, I., Pauli, J., and Reddy, M. (2014), "Paging 'Dr. Google': Does technology fill the gap created by the prenatal care visit structure? qualitative focus group study with pregnant women", Journal of Medical Internet Research, Vol. 16, e147, available at: https://doi.org/10.2196/jmir.3385

Krogstad, D. J., Diop, S., Diallo, A., Mzayek, F., Keating, J., Koita, O. A., and Touré, Y. T., (2010). "Informed consent in international research: the rationale for different approaches", The American Journal of Tropical Medicine and Hygiene, Vol. 83, pp. 743-747.

Lee, Y., and Moon, M. (2016), "Utilization and content evaluation of mobile applications for pregnancy, birth, and child care”, Healthcare Informatics Research, Vol. 22, pp. 73-80.

Lupton, D. (2016). "The use and value of digital media for information about pregnancy and early motherhood: a focus group study", BMC Pregnancy and Childbirth, Vol. 16.

Lutenbacher, M., Gabbe, P. T., Karp, S. M., Dietrich, M. S., Narrigan, S., Carpenter, L., and Walsh, W. (2014), "Does additional pre-natal care in the home improve birth outcomes for women with a prior preterm delivery? A randomized clinical trial", Maternal and Child Health Journal, Vol. 18, No. 5, 1142-1154.

Machado, M. F. A. S., Monteiro, E. M. L. M., Queiroz, D. T., Vieira, N., and Barroso, M. G. T. (2007), "Integralidade, formação de saúde, educação em saúde e as propostas do SUS - uma revisão conceitual". Ciência e Saúde Coletiva, Vol. 12, No. 2, pp. 335-342.

Madaj, B., Smith, H., Mathai, M., Roos, N., and van den Broek, N., (2017), "Developing global indicators for quality of maternal and newborn care: a feasibility assessment", Bulletin of the World Health Organization, Vol. 95, pp. 445-452, available at: http://dx.doi.org/10.2471/BLT.16.179531

Norris, S. L., and Ford, N. (2017). "Improving the quality of who guidelines over the last decade: progress and challenges", Lancet Glob Health., Vol. 5, e855-6.

Queensland Health (2017). Guide to Informed Decision-making in Health Care, Patient Safety and Quality Improvement Service, Clinical Excellence Division. $2^{\text {nd }}$ edition, Queensland, Australia.

Renfrew, M. J., McFadden, A., Bastos, M. H., Campbell, J., Channon, A. A., Cheung, N. F., . . . Declercq, E. (2014), "Midwifery and quality care: findings from a new evidence-informed framework for maternal and newborn care", The Lancet, Vol. 384, pp. 1129-1145.

Robinson, J. R., Anders, S. H., Novak, L. L., Simpson, C. L., Holroyd, L. E., Bennett, K. A., and Jackson, G. P. (2018). "Consumer health-related needs of pregnant women and their caregivers", JAMIA 
Open, Vol. 1, pp. 57-66.

Sartorius, N. (2006), "The meanings of health and its promotion", Croatian Medical Journal, Vol. 47, No. 4, pp. 662-664.

Say, L., Chou, D., Gemmill, A., Tunçalp, Ö., Moller, A. B., Daniels, J., . . Alkema, L. (2014), "Global causes of maternal death: a who systematic analysis", The Lancet Global Health, Vol. 2, e323333.

Sayakhot, P., Carolan-Olah, M., and Steele, C. (2016). "Use of a web-based educational intervention to improve knowledge of healthy diet and lifestyle in women with gestational diabetes mellitus compared to standard clinic-based education", BMC Pregnancy and Childbirth, Vol. 16.

Scott, K., Gome, G., Richards, D., and Caldwell, P. (2015), "How trustworthy are apps for maternal and child health? health and technology", Health and Technology, Vol. 4, pp. 329-336, available at: https://doi.org/10.1007/s12553-015-0099-x

Sinclair, M., Lagan, B. M., Dolk, H., and McCullough, J. E. M. (2018). "An assessment of pregnant women's knowledge and use of the internet for medication safety information and purchase", Journal of Advanced Nursing, Vol. 74, pp. 137-147.

Stirling, D., Vanbesien, J., and McDougall, R. (2018). Informed decision-making for labour and birth, Ontario Public Health Association.

Tripp, N., Hainey, K., Liu, A., Poulton, A., Pee, M., Kim, J., and Nanan, R. (2014), "An emerging model of maternity care: Smartphone, Midwife, Doctor?”, Women and Birth, Vol. 27, pp. 64-67, available at: https://doi.org/10.1016/j.wombi.2013.11.001

Tunçalp, Ö., Were, W. M., MacLennan, C., Oladapo, O. T., Gülmezoglu, A. M., Bahl, R., . . Bustreo, F. (2015), "Quality of care for pregnant women and newborns - the WHO vision”, BJOG, Vol. 122, pp. 1045-1049.

UNESCO (2013), Towards knowledge societies for peace and sustainable development. United Nations Educational, Scientific and Cultural Organization, Paris, France.

UNFPA (1995), Report of the international conference on population and development. United Nations Population Fund. Cairo, Egypt.

UNICEF (2018), Designing Digital Interventions for Lasting Impact: A Human-Centred Guide to Digital Health Deployment, UNICEF Health Section Implementation Research and Delivery Science Unit and the Office of Innovation Global Innovation Centre, available at:

https://www.unicef.org/innovation/media/511/file/Designing Digital Interventions for Lasting Impact.pdf United Nations General Assembly (1968), Universal Declaration of Human Rights, 217 (III), Paris, France, available at: https://www.un.org/en/about-us/universal-declaration-of-human-rights United Nations (1968). Final act of the international conference on human rights. New York, NY, USA.

United Nations (2015a). The Millennium Development Goals Report. 72.

United Nations (2015b). Transforming our world: the 2030 Agenda for Sustainable Development, 
General Assembley, 70 Session, Vol. 1630, pp. 1-35.

Wallwiener, S., Müller, M., Doster, A., Laserer, W., Reck, C., Pauluschke-Fröhlich, J., . . . Wallwiener, M. (2016), "Pregnancy eHealth and mHealth: user proportions and characteristics of pregnant women using Web-based information sources: a cross-sectional study." Archives of Gynecology and Obstetrics, Vol. 294, No. 5, pp. 937-944, available at: https://doi.org/10.1007/s00404-016-4093-y

WHO (2016), WHO Recommendations on antenatal care for positive pregnancy experience, World Health Organization Press, available at: http://apps.who.int/iris/bitstream/10665/250796/1/9789241549912-eng.pdf?ua=1

WHO (2018), WHO Recommendations: intrapartum care for a positive childbirth experience, World Health Organization Press, available at: http://apps.who.int/iris/bitstream/10665/260178/1/9789241550215-eng.pdf?ua=1

WHO (2019a), WHO Consolidated Guideline on Self-Care Interventions for Health: sexual and reproductive health and rights. World Health Organization: Human Reproduction Programme, Geneva, Switzerland, available at: https://apps.who.int/iris/bitstream/handle/10665/325480/9789241550550eng.pdf?ua=1

WHO (2019b), "WHO guideline: Recommendations on digital interventions for health system strengthening", World Health Organization: WHO/RHR/19.8, Geneva, Switzerland. Available at: https://apps.who.int/iris/bitstream/handle/10665/311977/WHO-RHR-19.8-eng.pdf?ua=1

WHO (2019c), "WHO digital accelerator kits", World Health Organization: Human Reproduction Programme, Geneva, Switzerland, available at: https://www.who.int/reproductivehealth/projects digitalaccelerator-kits-project-brief.pdf?ua $=1$

Zakerihamidi, M., Roudsari, R. and Khoei, E. (2015), "Vaginal Delivery vs. Cesarean Section: A Focused Ethnographic Study of Women's Perceptions in The North of Iran." International Journal of Community based Nursing and Midwifery, Vol. 3, pp. 50.

Zhu, C., Zeng, R., Zhang, W., Evans, R., and He, R. (2019). "Pregnancy-related information seeking and sharing in the social media era among expectant mothers in china: Qualitative study", Journal of Medical Internet Research, Vol. 21, e13694.

\section{Further Reading}

Ackerman, L. (2013), Mobile health and fitness applications and information privacy, Privacy Rights Clearing House, California Consumer Protection Foundation, available at: https://privacyrights.org/sites/ default/files/pdfs/mobile-medical-apps-privacy-consumer-report.pdf Dembosky, A. (2013), "Pregnancy apps raise fresh privacy concerns", The Financial Times, available at: http://www.ft.com/cms/s/0/1c560432-2782-11e3-ae16-00144feab7de.html axzz37gHqmHO7

Doty, J.L. and Dworkin, J. (2014), "Online social support for parents: a critical review”, Marriage \& 
Family Review, Vol. 50 No. 2, pp. 174-198.

Flemming, S.E., Vandermause, R. and Shaw, M. (2014), "First-time mothers preparing for birthing in an electronic world: internet and mobile phone technology", Journal of Reproductive and Infant Psychology, Vol. 32 No. 3, pp. 240-253.

Scott, K., Gome, G., Richards, D. and Caldwell, P. (2015), "How trustworthy are apps for maternal and child health? Health and technology", Health and Technology, Vol. 4 No. 4, pp. 329-336, available at: https://doi.org/10.1007/s12553-015-0099-x

Thomas, G.M. and Lupton, D. (2015), "Threats and thrills: pregnancy apps, risk and consumption", Health, Risk and Society, Vol. 17 Nos 7/8, pp. 495-509, available at: https://doi.org/10.1080/ 13698575.2015.1127333

WHO (2015), The MAPS Toolkit mHealth Assessment and Planning for Scale, World Health Organization Document Production Services, Geneva, available at: https://apps.who.int/iris/bitstream/handle/10665/ 185238/9789241509510_eng.pdf?sequence=1

\section{Citation}

Leite, C.V. and Almeida, A.M. (2021), "A framework proposal for digital interventions in perinatal education: the result of a content analysis to WHO intra-partum care recommendations", International Journal of Human Rights in Healthcare, Vol. 14 No. 3.

https://doi.org/10.1108/IJHRH-07-2020-0060

\section{Corresponding author:}

Carla V. Leite can be contacted at: carla.v.leite@gmail.com

Publisher:

Emerald Publishing Limited

Copyright (C) 2021, Emerald Publishing Limited

Available at: https://www.emerald.com/insight/content/doi/10.1108/IJHRH-07-2020-0060/full/html 